\title{
Analytical artifacts caused by the presence of water vapor in the headspace of food products
}

\author{
D. Canac-Arteaga, C. Viallon and J.-L. Berdagué* \\ Laboratoire Flaveur, Station de Recherches sur la Viande, INRA de Theix, 63122 Ceyrat, France
}

\begin{abstract}
Artifacts due to water that appear during analysis by purge-and-trap/GC/MS of naturally moist products were reproduced by increasing the relative humidity of the headspace of measuring cell containing dry and low-moisture products (dehydrated beef stock and powdered Parmesan cheese) by means of a piece of moistened glass wool. The changes observed in the chromatographic profiles of the dry products after humidifying the headspace are explained by interactions between volatile compounds, water and the adsorption trap during the purge-and-trap step.
\end{abstract}

Keywords. Food products - volatile compounds - purge-and-trap - artifacts and water.

\section{Introduction}

The analysis of the volatile fraction of food products is often carried out using the purge-and-trap technique coupled with high-resolution gas chromatography and mass spectrometry (PT-HRGC-MS). However, when this technique is applied to diverse foods, many volatile compounds present in large amounts in the food are often quantitatively underestimated or may even go undetected [1-6]. In the case of dynamic extraction followed by trapping of volatile compounds on an adsorbent, these artifacts are generally attributed to water [7-9], which is often the main volatile constituent of the foods. These artifacts can occur at any step in the analytical chain: purge-and-trap [10-11], gas chromatography [1213] and mass spectrometry [13-14].

The aim of the work reported here was to underscore major artifacts appearing during the purge-and-trap step of the volatile fraction analysis of water-rich products. For this purpose we humidified the headspace of dry and lowmoisture products to simulate the artifacts produced during the analysis of naturally moist products. This method implemented with and without dry purge of the trapping adsorbent also enabled us to determine the origin of the observed interference.

\section{Materials and methods}

\section{Samples}

Two food products of animal origin, namely dehydrated beef stock and powdered Parmesan cheese, were selected for their low water content (respectively 2.3 and $25.0 \%$ ) and for the diversity of the chemical families present in their volatile fractions.

\section{Description of experiments carried out}

To target the origin of the water-related artifacts, different analyses were carried out with and without humidification of the headspace of the products, and with and without a dry purge step. In all, eight analyses were performed: two products (dehydrated beef stock and Parmesan cheese) in two moisture states (dry and moist) with two drying states for the Tenax trap (with and without dry purge).

\section{Purge-and-trap of volatile components}

The volatile fraction of the products was analysed using a Tekmar LSC 2000 purge-and-trap instrument (Cincinnati, $\mathrm{OH} 45234$, USA). Four grams of a finely divided sample of each product was placed on glass wool (reference Prolabo $\mathrm{n}^{\circ} 23039.293$ ) at the bottom of a glass extraction cell (height: $70 \mathrm{~mm}$, external diameter: $34 \mathrm{~mm}$ ). The extraction cell was swept with the purge gas (helium, purity $=99.995 \%$, Air Liquide) at a flow rate of $60 \mathrm{ml} \cdot \mathrm{min}^{-1}$. The extractions were carried out at $19{ }^{\circ} \mathrm{C}$ for 20 min. The adsorbent used was Tenax 60/80 mesh, length $24 \mathrm{~cm}$, internal diameter $1 / 8$ inch (reference Supelco $\mathrm{n}^{\circ} 2$ 1059-U), operating temperature $30{ }^{\circ} \mathrm{C}$.

\section{Humidification of headspaces}

In preliminary tests two approaches were tried: (i) injection of moist helium into the headspace throughout the extraction using a make-up located between the extraction cartridge and the trap [11,15-17], and (ii) humidification of the atmosphere in the extraction cartridge using a piece of moistened glass wool. In principle the first approach offered the advantage of avoiding any risk of interaction between the moistened glass wool and the volatile components of the products, but it proved more difficult to implement

* Correspondence and reprints.

Received April 27, 2000; revised and accepted July 25, 2000. 
(particularly as regards the regulation of gas flow rates). As the tests showed that both approaches to humidification led to the same artifacts and that no noteworthy interaction could be observed between the moistened glass wool and the volatile components, the second approach, which was more workable, was selected. Thus the atmosphere in the extraction cartridge was humidified using $0.3 \mathrm{~g}$ of glass wool moistened with $1.4 \mathrm{ml}$ of distilled water fixed to a stainless steel rod to avoid contact with the products being analysed (Fig. 1).
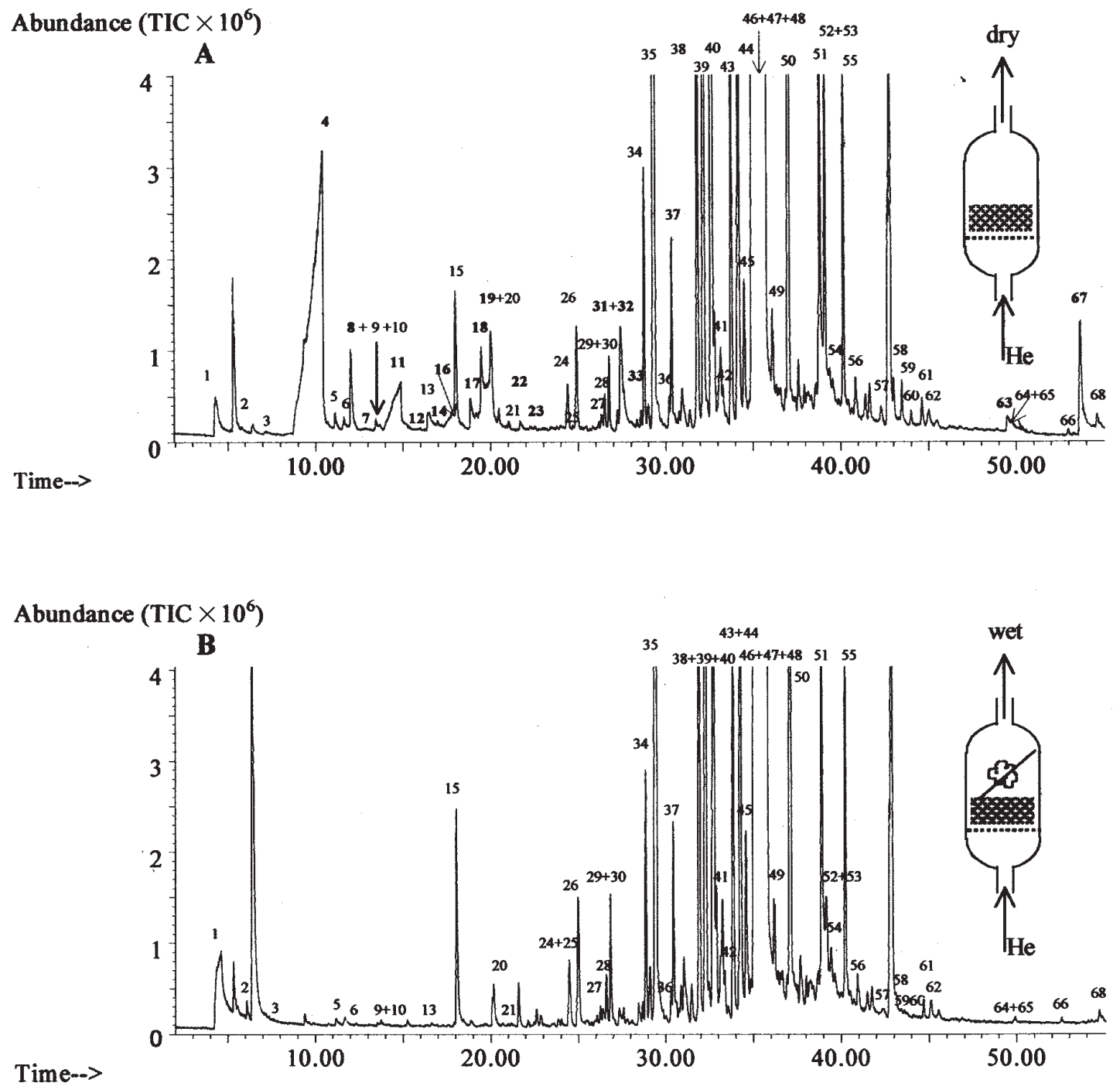

Figure 1. Comparison of chromatographic profiles of dehydrated beef stock analysed without (A) and with added water (moist glass wool) (B) in the headspace of the extraction cartridge after a purge of $20 \mathrm{~min}$ and a dry purge of $3 \mathrm{~min}$.

The different compounds identified in this product are numbered from 1 to 68 . The peaks with numbers in bold type are those of compounds that have disappeared from the chromatogram after humidifying the headspace. $1=$ water, $2=2$-propanone, $3=2$-methyl propanal, 4 = acetic acid, $5=3$-methyl butanal, $6=2$-methyl butanal, $7=\mathbf{1}$-penten-3-ol, $8=\mathbf{2 , 3}$-pentanedione, $9=$ pentanal, $10=$ heptane, 11 = propanoic acid, $12=3$-methyl butanol, $13=$ dimethyl disulfide, $14=1$,2-butanediol, $15=$ toluene, $16=$ propanoic acid, 2-methyl, $17=$ 1,3-butanediol, $18=$ 2,3-butanediol, $19=$ butanoic acid, $20=$ hexanal, 21 = acetic acid, butyl ester, $22=$ methyl pyrazine, 23 = 2-methyl, 2-pentenal, $24=$ m-xylene, $25=$ hexanol, $26=$ p-xylene, $27=$ styrene, $28=0$-xylene, $29=$ nonane, $30=$ heptanal, $31=$ 2,6-dimethyl pyrazine, 32 = gamma butyrolactone, $\mathbf{3 3}=$ dimethyl sulfone, $34=$ alpha-thujene, $35=$ alpha-pinene, 36 fenchene, $37=$ camphene, $38=$ sabinene, 39 = beta-pinene, $40=$ beta myrcene, $41=$ decane, $42=$ octanal, $43=$ alpha-phellandrene, $44=3$-carene, $45=$ alpha-terpinene, $46=$ m-cymene, $47=$ p-cymene, $48=$ limonene, $49=$ ocimene, $50=$ gamma terpinene, $51=$ terpinolene, $52=$ undecane, $53=$ linalool, $54=$ nonanal, $55=1,3,8$ p-menthatriene, $56=$ alpha pyronene, $57=$ camphor, $58=$ isoborneol, $59=$ borneol, $60=4$-terpineol, $61=$ dodecane, $62=$ estragol, $63=$ thymol, $64=$ bornyl acetate, $65=$ tridecane, $66=$ delta elemene, $\mathbf{6 7}=$ eugenol, $68=$ alpha-copaene. 


\section{Measurement of relative humidity}

The relative humidity in the headspace of the extraction cartridge was measured using a I155CI hygrometry probe (Rotronic, Switzerland) made of a Hygromer ${ }^{\circledR}$ polymer, the dielectric properties of which vary with the humidity of the atmosphere. Continuous measurement was used during the purge-and-trap step for each product with and without added water. The signal was sent to an AOIP SA32 processor equipped with AOIP LW1 software (PB Mesures, 63110 Beaumont, France). The software was used to follow the relative humidity throughout the extraction (20 minutes), and the plateau value of the relative humidity was recorded.

\section{Elimination of the water retained on the adsorbent using the dry purge method}

This operation consisted in drying with helium to eliminate some of the water retained on the Tenax during the trapping of the volatile components. The analyses (with or without humidifying the headspaces of the samples) were carried out with and without dry purge. The duration of the dry purge step was set at three min with a flow-rate of $60 \mathrm{ml} . \mathrm{min}^{-1}$ [18].

\section{Injection of volatile components into the capillary column}

The volatile components were desorbed from the Tenax at $180{ }^{\circ} \mathrm{C}$ for $5 \mathrm{~min}$ using helium (purity $=99.9995 \%$, Air Liquide) as carrier gas with a flow rate of $1.4 \mathrm{ml} \cdot \mathrm{min}^{-1}$. They were then cryofocused at $-150{ }^{\circ} \mathrm{C}$ in a $3 \mathrm{~cm}$ segment of a deactivated fused silica precolumn (internal diameter: $0.53 \mathrm{~mm}$, length: $1.5 \mathrm{~m}$, Varian) using a liquid nitrogen cooling system. The injection in splitless mode onto the chromatography column was then carried out by heating the precolumn for $2 \mathrm{~min}$ at $225{ }^{\circ} \mathrm{C}$. To eliminate any potential memory effects between successive analyses, the Tenax trap was then heated ("bake") for $20 \mathrm{~min}$ at $180{ }^{\circ} \mathrm{C}$.

\section{Separation, detection and identification of the volatile components}

The volatile components were separated with a capillary column (SPB5, film thickness: $1 \mu \mathrm{m}, 60 \mathrm{~m} \times 0.32 \mathrm{~mm}$; Supelco). The oven temperature of the chromatograph (Hewlett Packard 5890) was programmed as follows: 5 min isotherm at $33{ }^{\circ} \mathrm{C}$, heated at $3{ }^{\circ} \mathrm{C} \mathrm{min}-1$ up to $200{ }^{\circ} \mathrm{C}$, then $2 \mathrm{~min}$ hold at $200{ }^{\circ} \mathrm{C}$. The volatile components were detected by mass spectrometry with electron impact at $70 \mathrm{eV}$ (Hewlett Packard 5971S). Data acquisition was set at 3 scan. $\mathrm{s}^{-1}$ applied over the ion mass range 15 to 205 daltons. The volatile components were identified by comparing their spectra with those of the NBS 75K database (1994), and their retention indices with those of the database compiled by Kondjoyan and Berdagué (1996) [19].

\section{Calculation of peak area}

The peak area of the volatile components (arbitrary units of area, a.u.a.) was integrated from specific ions for each of the molecules to circumvent co-elution problems. The integrations were performed with MSD ChemStation software from Hewlett Packard. The integration parameters were as follows: initial detection threshold: 8 a.u.a.; initial peak width: $0.2 \mathrm{~min}$; minimum peak area: 10,000 a.u.a.

\section{Results and discussion}

The moist glass wool increased the headspace relative humidities of the dehydrated beef stock and the powdered Parmesan cheese from $27 \%$ to $77 \%$ and from $62 \%$ to $75 \%$ respectively.

This increase in the relative humidity of the headspace markedly modified the chromatographic profiles of the dehydrated beef stock (Fig. 1) and the powdered Parmesan cheese in the analyses performed with a dry purge step. These modifications appeared despite the low water retention on the non-polar porous polymer of the Tenax adsorbent $[7,20]$. Thus the areas of approximately $40 \%$ of the peaks were strongly modified and 21 out of 79 peaks disappeared from the chromatographic profiles (Tab. I). These disappearances occurred mainly in the first part of the chromatogram in the range of relative retention indices between 550 and 925 (Fig. 2). The detailed results in table I show that most of the peaks missing from the chromatograms corresponded to the most polar compounds, i.e., aliphatic or cyclic compounds of low molecular weight bearing one or more atoms of oxygen or nitrogen, such as carboxylic acids, alcohols, lactones, pyrazines or ketones. In contrast, the areas of the peaks corresponding to apolar compounds such as alkanes, aromatic hydrocarbons or terpenes were barely affected by adding water to the headspace. Peaks of aldehydes and esters with more than five atoms of carbon likewise remained stable. These results confirm the good performance of purge-and-trap systems using adsorbent traps of the Tenax type to analyse apolar components (aromatic or terpene compounds, alkanes, solvents, organochloride pesticides, etc.) present in water or aqueous materials [21-22]. They also confirm the poor performance observed in the analysis of short-chain fatty acids in dairy products [1-6]. For example cheese containing more than $1 \%$ short-chain carboxylic acids by weight has been analysed by PT-HRGCMS without detecting the least trace of such compounds, even as their specific ions $(\mathrm{m} / \mathrm{z}=60$ for acetic, 73 for isovaleric and 74 for propionic acids) [unpublished data].

For dairy products, the water naturally present in their matrix rapidly saturates the headspace, causing artifacts similar to those we have induced by humidifying the headspace of the two low-moisture products. In contrast, in salt-cured products in which water activity is very low (high salt and low water contents), the analysis of carboxylic acids and polar substances is possible [23-24]. Even so, the proportions of these acids relative to the other compounds present in the chromatography profile are always greatly underestimated. 
Table I. Effect of addition of water on the peak areas of the different volatile compounds extracted from dehydrated beef stock (B), powdered Parmesan cheese $(\mathrm{P})$ or both products $(\mathrm{B}, \mathrm{P})$. Three types of behavior were observed for the volatile components after addition of water to the headspace: (i) decrease of the peak area by more than $50 \%$ or complete disappearance of the peak from the chromatogram (compounds in bold type), (ii) increase of the peak area by more than $50 \%$, and (iii) no major change (stable). The aliphatic and cyclic compounds are listed in decreasing order of polarity.

Variation of peak area of volatile components of dehydrated beef stock and powdered Parmesan cheese after addition of water

Decrease of more than $50 \%$ Stable peak areas

Increase of more than $50 \%$

$\begin{array}{ll}\begin{array}{l}\text { ALIPHATIC COMPOUNDS } \\ \text { WATER }\end{array} & \text { acetic acid (B, P) } \\ \text { ACIDS } & \text { propanoic acid (B, P) } \\ & \text { propanoic acid, 2-methyl (B) } \\ & \text { butanoic acid (B, P) } \\ & \text { ethanol (P) } \\ & \text { propanol (P), 1,2-butanediol (B), } \\ & \mathbf{1 , 3 - b u t a n e d i o l ~ ( B ) , ~ 2 , 3 - b u t a n e d i o l ~ ( B ) , ~} \\ \text { ALCOHOLS } & \text { 1-penten-3-ol (B), 2-pentanol (P), } \\ & \text { butanol, 3-methyl (B), } \\ & \text { linalool (B) } \\ & \mathbf{2 , 3 - b u t a n e d i o n e ~ ( P ) ~} \\ & \text { 6-methyl-5-hepten-2-one (P) } \\ & \text { 2-nonanone (P) } \\ \text { KETONES } & \text { ethyl acetate (P) } \\ & \text { acetic acid, butyl ester (P) }\end{array}$

ALDEHYDES pentanal (B)

2-methyl, 2-pentenal (B)

hexanol (B)

acetone (B)

2-butanone $(\mathrm{P})$

2-pentanone $(\mathrm{P})$

2-heptanone $(\mathrm{P})$

butanoic acid, ethyl ester $(\mathrm{P})$

acetic acid, butyl ester (B)

bornyl acetate (B)

butanal, 3-methyl (B, P)

propanal, 2-methyl (B, P)

pentanal $(\mathrm{P})$

butanal, 2-methyl (B, P)

hexanal $(\mathrm{B}, \mathrm{P})$, heptanal $(\mathrm{B})$

octanal (B)

heptane (B), undecane (B) nonane (B)

dodecane $(\mathrm{B})$, tridecane $(\mathrm{B})$ water $(\mathrm{B}, \mathrm{P})$

acetone $(\mathrm{P})$

nonanal (B)

SULFUR COMPOUNDS dimethyl sulfone (B)

dimethyl disulfide (B, P)

\section{CYCLIC COMPOUNDS}

PHENOLS

LACTONES

PYRAZINES

TERPENOLS

AROMATIC

COMPOUNDS

TERPENES

and derivatives thymol (B), eugenol (B)

$\gamma$-butyrolactone (B)

methyl pyrazine (B)

2,6-dimethyl pyrazine (B)

isoborneol (B), borneol (B),

4-terpineol (B)

$\alpha$-pinene (B) toluene $(\mathrm{B}, \mathrm{P}), \mathrm{m}$-xylene $(\mathrm{B}, \mathrm{P})$, p-xylene $(B, P)$, styrene $(B, P)$, o-xylene (B, P), m-cymene (B, P), p-cymene (B, P), estragol (B)

$\alpha$-pinene $(\mathrm{P})$

$\alpha$-thujene (B), fenchene (B), camphene (B), sabinene (B), $\beta$-pinene (B, P), $\beta$-myrcene (B), $\alpha$-phellandrene (B), 3-carene (B, P), $\alpha$-terpinene (B), limonene (B, $\mathrm{P}$ ), ocimene (B), $\gamma$-terpinene (B), terpinolene (B),

1,3,8 p-menthatriene (B),

$\alpha$-pyronene (B), camphor (B)

$\delta$-elemene (B), $\alpha$-copaene (B) 


\section{Original articles}

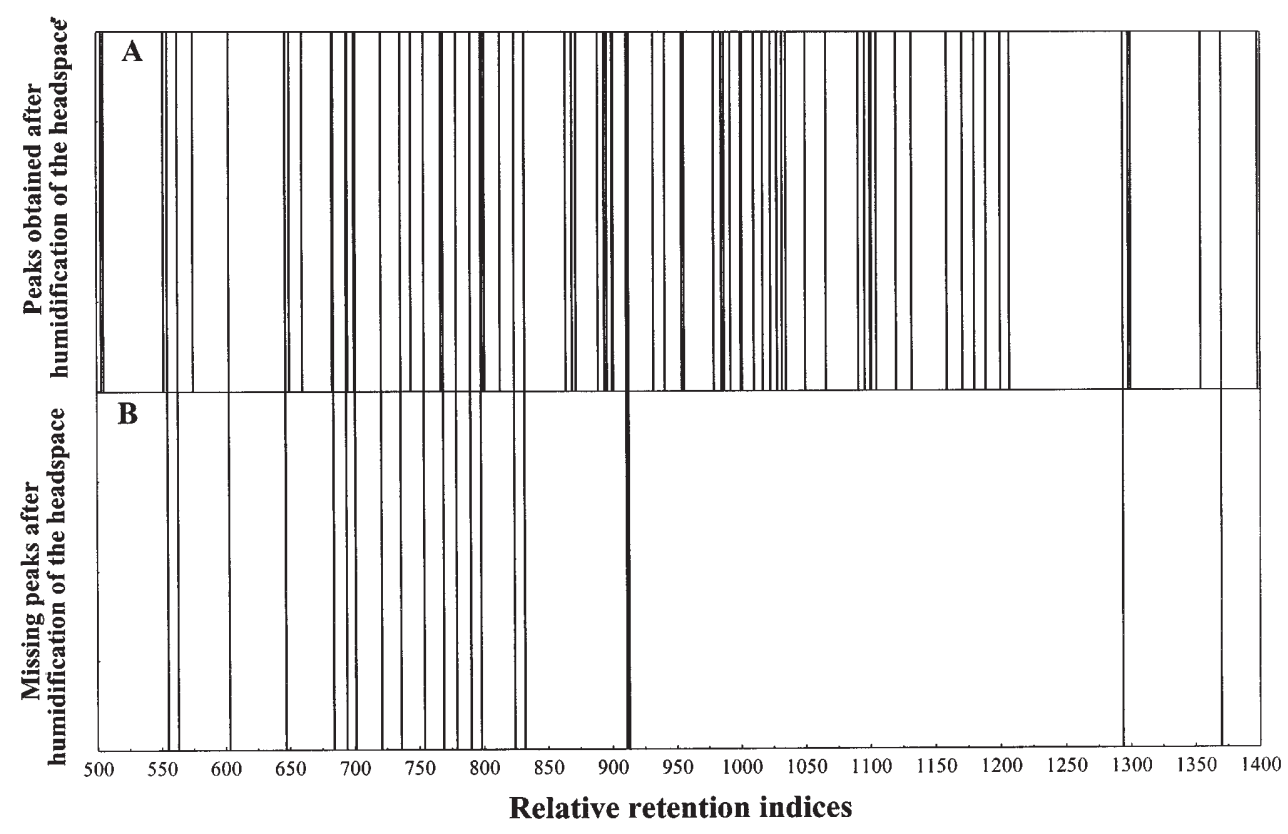

Figure 2. Distribution of chromatographic peaks of dehydrated beef stock and powdered Parmesan cheese as a function of their relative retention indices (IK).

A: set of peaks obtained before humidification of the headspace. B: set of missing peaks after humidification of the headspace. The names of the lost components are indicated in bold type in table I.
Two hypotheses could be advanced to account for the observed artifacts. The first was that the moist glass wool interacted directly with the volatile components desorbed from the products. This was ruled out in preliminary tests in which moist helium injected in the purge-and-trap step using a make-up located between the extraction cartridge and the trap caused the same artifacts as those observed with moist glass wool. In addition, the olfactive comparison of the volatile components released by the two products carried out in extraction conditions similar [25] to those of the current PT-HRGC-MS analyses did not show any difference regardless of whether or not moist glass wool was present in the extraction cartridge. A difference would have been observed at least if the disappearance of the carboxylic acids were fully attributable to mechanisms of adsorption on the moist glass wool.

The second hypothesis advanced to account for the disappearance of the volatile components after humidification of the headspace was that water and volatile components were in competition for adsorption on the Tenax trap. To investigate this possibility analyses were carried out without any dry purge. The different possibilities of adsorption on the Tenax with and without a dry purge step and with and without humidification of the headspace are schematized for the particular case of acetic acid and water (Fig. 3). Detailed analysis of the results presented in figure 3 clearly indicated that the water added to the headspace of the two products causes the acetic acid to disappear in the purge-and-trap step but not in the dry purge step. This loss is explained by nonretention of acetic acid on the Tenax trap in the purge-andtrap step (hypothesis H3 and H31, Fig. 3B). With no dry purge, because the injections were splitless, retention of acetic acid on the trap should have resulted in a corresponding chromatogram peak (hypothesis H4, Fig. 3B), which was not observed experimentally.

More generally, a compound-by-compound study showed that the disappearance of the most polar substances after addition of water could be explained in the same way as the disappearance of the acetic acid, i.e., by non-retention on the trap during the purge-and-trap step. This non-retention of compounds in the presence of water is due to both competitive mechanisms of adsorption/desorption between water, volatile components and the Tenax trap, and by the formation of hydrogen bonds in the gas phase between water and polar volatile compounds [15]. These mechanisms also explain a weakened retention of compounds on the Tenax in the presence of water [11]. However, the presence of water on the Tenax trap does not modify the adsorption of apolar volatile components [16-17,26].

\section{Conclusion}

This study shows that the trapping of volatile components on a Tenax-type adsorbent can be highly sensitive to the relative humidity in the headspace of the product being analysed. It is demonstrated that during the analysis by PTGC-MS of moist products many polar compounds are not retained on the adsorbent during the purge-and-trap step. The non-detection of these compounds (carboxylic acids, alcohols, etc.) is problematic when the interest of the study is the biochemistry or the aroma of the food. In contrast, the analysis of apolar products is evidently unaffected by the relative humidity in the headspace of the product. 
$\mathbf{A}$

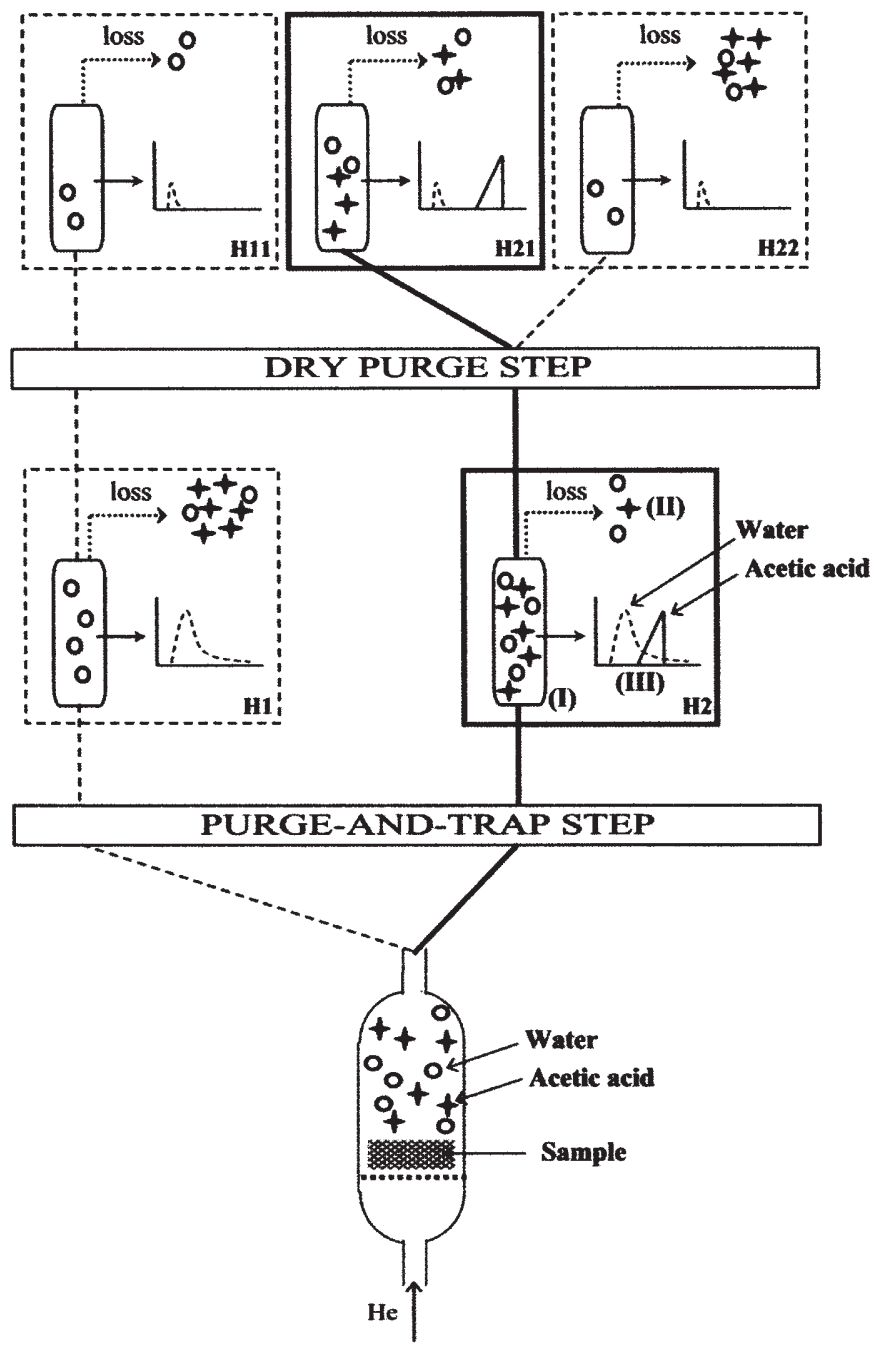

\author{
Without humidification \\ of the cell headspace
}

\section{B}

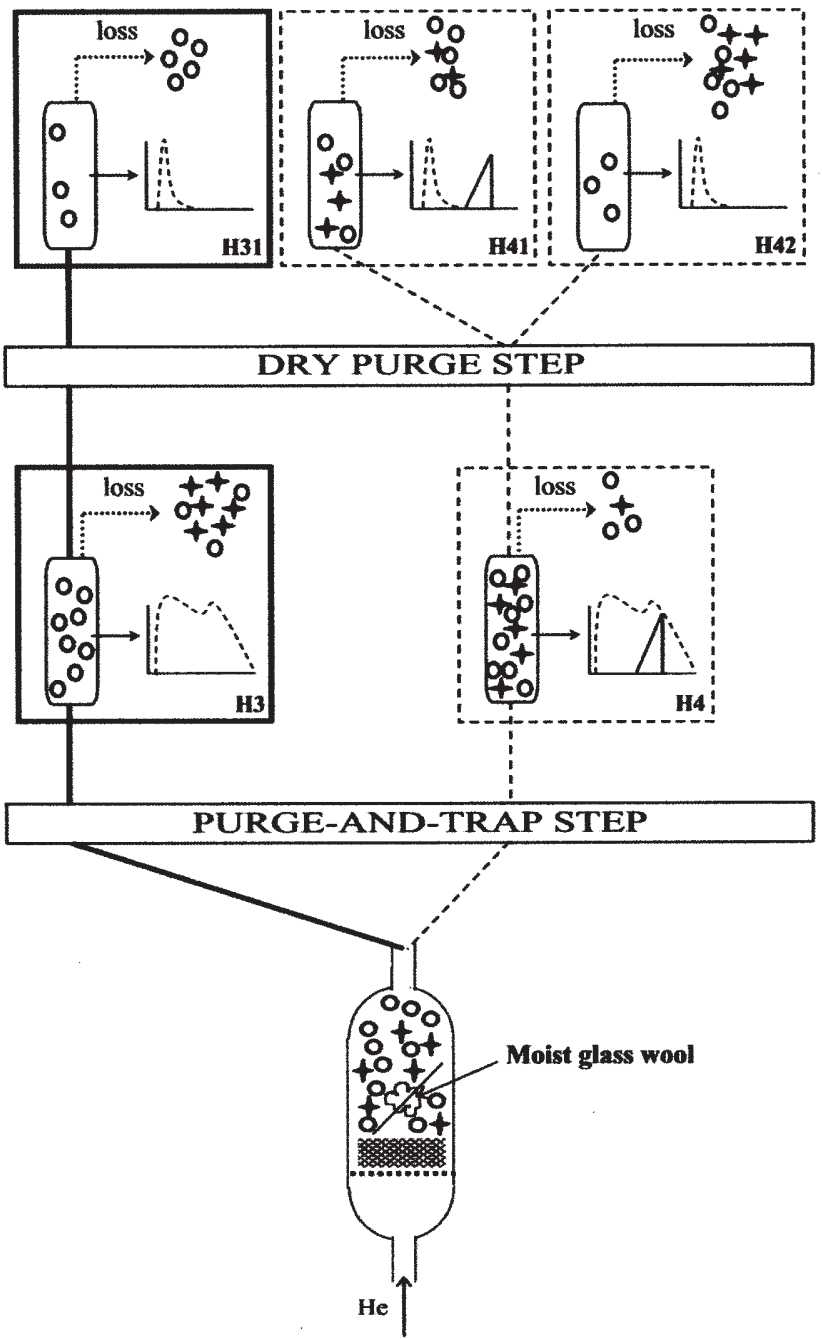

With humidification
of the cell headspace

Figure 3. Diagram showing the ten hypotheses for the competing adsorption of volatile compounds and water on the Tenax trap during the purge-and-trap and dry purge steps, with and without humidification of the headspace of the products.

For simplicity only two volatile compounds are considered; water (o) and acetic acid (+). Also, of all the hypotheses possible for the adsorption of these volatile compounds on the Tenax trap only those of adsorption of water and acetic acid or adsorption of water alone on the Tenax trap were considered. The other theoretical possibilities, i.e., adsorption of acetic acid alone, non-adsorption of acetic acid and non-adsorption of water were ruled out by practical experience. To explain the disappearance of acetic acid after addition of water to the headspace of the products ten hypotheses from the analytical steps of purge-and-trap with no dry purge, and purge-and-trap with dry purge with and without addition of water were made. In hypothesis $\mathrm{H} 2$ a large proportion of the acetic acid is adsorbed with water on the Tenax trap (I) and losses by venting are limited (II). This hypothesis affords a theoretical chromatogram (III) where water and acetic acid peaks should be observed between 4 and 12 minutes. Comparison of the theoretical and experimental chromatograms identifies the analytical step responsible for the disappearance of certain compounds after addition of water in the headspace of the products. When a hypothesis was supported by analytical results it is boxed with a continuous line. When the hypothesis was refuted it is boxed with a dashed line.

Lastly, when no water was added to the headspace of the products (A), only hypotheses $\mathrm{H} 2$ and $\mathrm{H} 21$ were supported by the analyses. This means that the water and the acetic acid were adsorbed on the Tenax trap during the purge-and-trap step and that the dry purge step eliminated neither the acetic acid nor all the water.

In the presence of water (B) hypotheses H3 and H31 (boxed on the figure) were supported by the analytical results, indicating that the acetic acid was not adsorbed on the Tenax trap during the purge-and-trap step. 


\section{Original articles}

\section{References}

1. Christensen, T. C.; Hølmer, G. Milchwissenschaft 1996, 51, 134-138.

2. Contarini, G.; Toppino, P. M. Int. Dairy Journal 1995, 5, 141155.

3. Ott, A.; Fay, L. B.; Chaintreau, A. J. Agric. Food Chem. 1997, $45,850-858$.

4. Vallejo-Cordoba, B.; Nakai, S. J. Agric. Food Chem. 1993, 41, 2378-2384

5. Yang, W. T.; Min, D. B. Journal of Food Science 1994, 59, 1309-1312.

6. Thierry, A.; Maillard, M.-B.; Le Quéré, J.-L. Int. Dairy Journal 1999, 9, 453-463

7. Helmig, D.; Vierling, L. Anal. Chem. 1995, 67, 4380-4386.

8. Hinshaw, J. V. LC-GC International 1990, 3, 22,24-26.

9. Pankow, J. F. Environ. Sci. Technol. 1991, 25, 123-126.

10. Ciccioli, P.; Cecinato, A.; Brancaleoni, E.; Frattoni, M.; Liberti, A. J. High Resol. Chromatogr. 1992, 15, 75-84.

11. Fabbri, A.; Crescentini, G.; Mangani, F.; Mastrogiacomo, A.R.; Bruner, F. Chromatographia 1987, 23, 856-860.

12. Chen, G.-C.; Rohwer, E. R. J. Chromatogr. A 1999, 845, 4352.

13. Rosen, M. E.; Pankow, J. F. J. Chromatogr. 1991, 537, 321328.

14. Westendorf, R. Environmental lab. 1992, 24, 36-39.
15. Janak, J.; Ruzickova, J.; Novak, J. J. Chromatogr. 1974, 99, 689-696.

16. Pellizzari, E. D.; Bunch, J. E.; Berkley, R. E.; McRae, J. Analytical Letters 1976, 9, 45-63.

17. Steinhanses, J.; Schoene, K. J. Chromatogr. 1990, 514, $273-$ 278.

18. Canac-Arteaga, D.; Viallon, C.; Berdagué, J.-L. Analusis 1999, 27, 780-785.

19. Kondjoyan, N.; Berdagué, J.-L. A compilation of relative retention indices for the analysis of aromatic compounds; Clermont-Ferrand: Laboratoire Flaveur, 1996.

20. Gawlowski, J.; Gierczak, T.; Jezo, A.; Niedzielski, J. Analyst 1999, 124, 1553-1558.

21. Driss, M. R.; Bouguerra, M. L. Intern. J. Environ. Anal. Chem. 1991, 45, 193-204.

22. Hino, T.; Nakanishi, S.; Hobo, T. J. Chromatogr. A 1996, 746, 83-90.

23. Berdagué, J.-L.; Monteil, P.; Montel, M. C.; Talon, R. Meat Sci. 1993, 35, 275-287

24. Viallon, C.; Berdagué, J.-L.; Montel, M. C.; Talon, R.; Martin, J. F.; Kondjoyan, N.; Denoyer, C. Food Research International 1996, 29, 667-674.

25. Rousset-Akrim, S.; Martin, J. F.; Bayle, M. C.; Berdagué, J. L. International Journal of Food Science and Technology 1997, 32, 539-546.

26. Brown, R. H.; Purnell, C. J. J. Chromatogr. 1979, 178, 79-90. 